reid überhaupt beffer werden for, aber es ift eine Şerfulebs=2robeit, Den tiefen Sđlamm biefes in Dem Bitreaufratismus verfnöđerten Beamtenthums zu betwältigen.

v, Berg.

\title{
马ng
}

\section{(Fin wei}

Fuf Den Jagden Sr. אönigl. Şoheit des łrinzen Griedrí von $\mathfrak{B}$ ủrttemberg im Rebieramte Rleinafpah, Forfta Reidenberg, befand fíd biz jum Sahre 1866 ein jehr guter Rehftand, befonders aber in Der fogenamifen Saardt, welđer Bald yon verifiedenen Bemeinden gepnchtet worden, zmifien

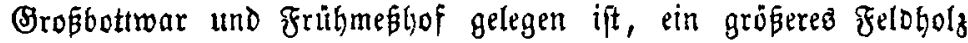
yon circa 3000 Morgen bildet.

In Diejer Gagd wurie feit 1865 ein wei Ber Rehbod gejehen, Der zu Wurfang 1865 nud einen grauen 5 als und Fiopf hatte und bei einer am 30. Sanune 1866 abgehaltenen Jago bon zwei

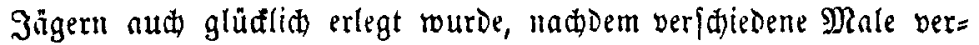
geblid auf Den Boct getrieben worden war.

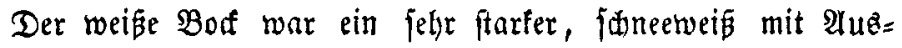
nahme einzelner ifabellfarbener Şaare auf Den Bügen, Gatte ftart

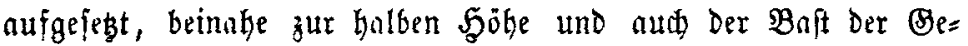

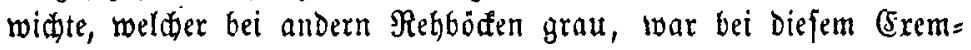
plare ianeerweín. Ter Bof wurde una ufgebroden an Se.

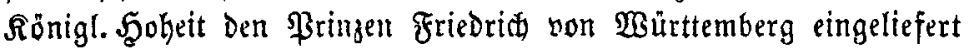
und bon Dem bohen Sgerrn Dem Naturalientabinette gefकenft; es

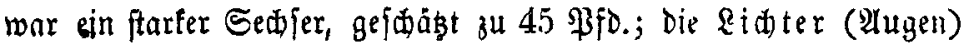
wurben son mir genalu unterfuctit, indem fie tei weikem $\Re(f)=$

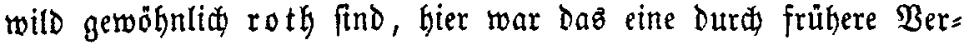
leģung blind, Daher verglažt, Daz andere wie bei allen Reken.

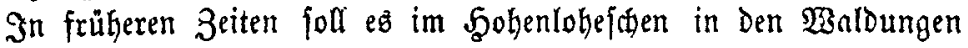

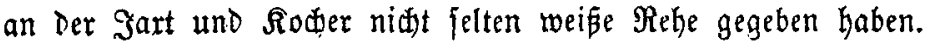

Dem Unterzeidneten ift in Kiefinger Bregend auker biefem in Der $\mathfrak{S}$ aard gefdoffenten nur nod einer vorgefommen und zroar auf

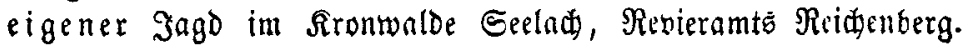




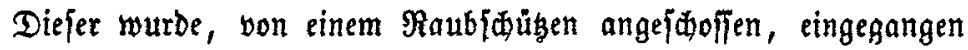
gefunden, aber früher oft gejeken, war ein frarfer Sedffer mit aufs fallend lïhtgelben Etangen, Den mein feliger $\mathfrak{B}$ nter forglam idionte, weil er vergeblich hoffte, bak non ifm aud weike Enaifen fallen würden. ReiDer wirb die $\mathfrak{B i l}$ derei wie faft überall in $2 B u ̈ r t t e m=$ berg, fo auth hier, in grosem umfange betrieben und geht oas Fangen in Drahtifilingen fo fort, waz namentlid in foneelofen

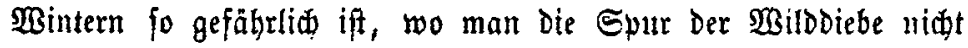
verfolgen fann, fo wird in ein paar Sahren aud ein gewöhnlider Relbbof hier zu ben jeltenen Thieren gefören.

Oppenweiler, den 19. April 1866.

freiberr v. Sturmfeòer.

\section{Iiterari/dse $\mathbf{B}$ erid)te.}

Nö. 17.

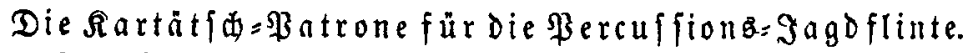
Epecielle Unwefung zur Şerftellung Diejes nad ei: gener (Exfindung conftruirten Nunitionzft ứ

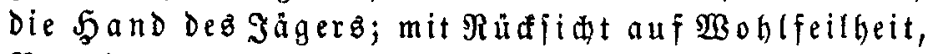
Bermittlung eines äuber finellen uno bequemen Radellb, wie aud wirlfamen $\subseteq$ dujfeb. Mit zwölf Daz $\mathfrak{B}$ erfabrenerläuternden 3 eiđanungen. Bongulius $\mathfrak{R} \mathfrak{b} \mathfrak{r}, \mathfrak{i o n i g l . ~ S a l i n e n f o ̈ r}$ ter in Swönebef bei $\mathfrak{R} n g=$ Deburg. 3weite Auflage. S更önebed 1865. Berlag yon Ernft Berger. 14 Seiten, Breis 1/4 Thlr.

$\mathfrak{u}$ uljere Jugdwaffet baben in Den leģten Gahren namentlia hin=

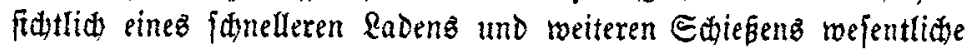
Berbefierungen erfahren und tie Eefaudeur= Serwehre haben find,

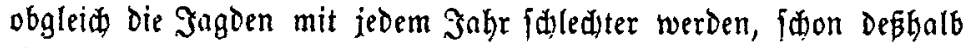
einen raften (singang verfđafft, weil viele Der jekigen Sngoliebhaber, meift Der Elafje Der ßapitaliften angehörig, mehr auff eine elegante

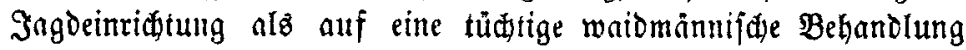
Der Эagd feken, und Darum Den Mehraufwand für Die Bejđaffung Des neueften Sagdapparatez nidjt zu fideuen brautien.

Solthen elegant aub̆geftatteten Jägern gegenüber måffen viele

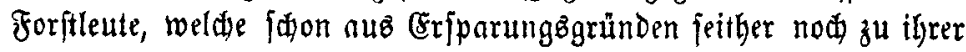

